\title{
Transforming growth factor- $\beta 1$-induced podocyte injury is associated with increased microRNA-155 expression, enhanced inflammatory responses and MAPK pathway activation
}

\author{
XINTONG ZHENG ${ }^{1 *}$, QIUHONG ZHONG ${ }^{2 *}, \mathrm{XU} \mathrm{LIN}^{1}, \mathrm{XIANJUN} \mathrm{GU}^{1}, \mathrm{XIAOYAN} \mathrm{LING}^{1}$, \\ ZHAO LIANG $^{1}$, QING QIN $^{1}$ and XIURI DU ${ }^{1}$ \\ Departments of ${ }^{1}$ Nephrology; and ${ }^{2}$ Ultrasound, The Affiliated Hospital of Youjiang \\ Medical University for Nationalities, Baise, Guangxi 533000, P.R. China
}

Received January 19, 2020; Accepted March 19, 2021

DOI: $10.3892 /$ etm.2021.10052

\begin{abstract}
MicroRNA-155 (miR-155) is associated with various diseases. However, the potential role of miR-155 in early glomerular disease (EGD) remains elusive. In the present study, the clinical significance of urinary miR-155 expression was explored in patients with EGD using receiver operating characteristic curve analysis. Conditionally immortalized mouse podocytes were cultured in vitro and treated with transforming growth factor- $\beta 1$ (TGF- $\beta 1$ ) at different concentrations and durations. The gene expression levels of mRNAs and miR-155 were detected using reverse transcription-quantitative PCR. Synaptopodin, CD2-associated protein (CD2AP), p38, and extracellular signal-regulated kinase (Erk) 1/2 expressions were detected using western blotting. Cell supernatants were collected for assaying tumor necrosis factor (TNF)- $\alpha$ and interleukin (IL)-6 concentrations using enzyme-linked immunosorbent assay. The Pearson correlation analysis was used to analyze the correlation between miR-155 levels and TNF- $\alpha$ or IL-6. It was found that miR-155 levels in urine have high sensitivity and specificity in the diagnosis of EGD. Time- and dose-dependent TGF- $\beta 1$ treatments downregulated
\end{abstract}

Correspondence to: Dr Xu Lin, Department of Nephrology, The Affiliated Hospital of Youjiang Medical University for Nationalities, 18 Zhongshan 2nd Road, Baise, Guangxi 533000, P.R. China

E-mail: linyyfyy@163.com

*Contributed equally

Abbreviations: miR-155, microRNA-155; EGD, early glomerular disease; CD2AP, CD2-associated protein; Erk, extracellular signal-regulated kinase; TNF, tumor necrosis factor; IL, interleukin; FPs, foot processes; TGF- $\beta$, transforming growth factor- $\beta$; MAPK, mitogen-activated protein kinase; ROC, Receiver operating characteristic; AUC, area under the ROC curve; ELISA, enzyme-linked immunosorbent assay

Key words: podocyte injury, TGF- $\beta 1$, miR-155, MAPK, inflammation synaptopodin and CD2AP expression levels, and activated the p38 and Erk 1/2 pathway. However, these effects were attenuated by p38 and Erk 1/2 phosphorylation inhibitors. Additionally, TNF- $\alpha$ and IL-6 secretions were elevated, and their concentrations were positively correlated with the expression of miR-155 during podocyte injury. Thus, the present study indicated that miR-155 is a potential biomarker for the diagnosis of EGD, and its expression is associated with the release of pro-inflammatory cytokines and activation of mitogen-activated protein kinase (MAPK) pathway in TGF- $\beta 1$-induced podocyte injury. The present study suggests that the TGF- $\beta 1 / \mathrm{miR}-155 / \mathrm{MAPK}$ axis is a novel target in the mechanism of EGD.

\section{Introduction}

Proteinuria is one of the most common clinical manifestations of early glomerular disease (EGD) with complicated mechanisms. It is agreed by most scholars that proteinuric EGD in patients is often associated with podocyte dysfunction $(1,2)$. Podocytes possess special cell structure comprising interdigitating foot processes (FPs) that bridge with the slit diaphragms and become part of the glomerular membrane, which can regulate renal ultrafiltration (3). Due to the presence of proteins, such as highly interconnected actin cytoskeleton, podocytes can adapt to environmental changes, maintain the cell morphology and integrity, and sustain a complete glomerular filtration barrier $(4,5)$. Synaptopodin is a proline-rich actin-associated protein expressed in highly dynamic cell compartments, such as podocyte FPs (6), and is critically involved in the development and maintenance of the podocyte contractile apparatus (7). CD2-associated protein (CD2AP), which is an SD protein, functions as an adaptor molecule involved in podocyte homeostasis that can repress proapoptotic transforming growth factor- $\beta$ (TGF- $\beta$ ) signaling in podocytes (8). Therefore, the expression levels of synaptopodin and CD2AP are often reversely correlated with the degree of podocyte injury. In addition, the importance of the correlation between inflammatory, immune, and etiological factors resulting in podocyte injury in glomerular diseases is not negligible (9). For example, in diabetic nephropathy, high 
expression levels of TGF- $\beta 1$, a multifunctional cytokine in immune regulation, are associated with podocyte injury and extracellular matrix deposition (10).

Mounting evidence suggests that miRNA plays a major role in several human diseases, including tumor, hematologic diseases and autoimmune disorders (11). The studies on the knockout of miRNA components showed that alterations of miRNA expressions affected cell phenotypes and produced a series of consequences (12). MicroRNA-155 (miR-155) has several important physiological functions, particularly in immune cells (13). It was previously demonstrated that the severity of renal injury could be alleviated by decreasing the expression levels of miR-155 in mouse podocytes (14). It was demonstrated that TGF- $\beta 1$ impaired the protein expression of nephrin and amplified the protein expression of desmin and caspase- 9 via activating the miR-155 signal pathway. Inhibition of miR-155 alleviated these changes in podocytes treated with TGF- $\beta 1$ and attenuated apoptosis. However, the clinical values of miR-155 in the diagnosis of podocyte injury and its association with podocyte inflammation have not been extensively elucidated so far.

Mitogen-activated protein kinase (MAPK) pathway is known for promoting the development of inflammation. Previous studies have shown that the process of podocyte injury was accompanied with the activation of the MAPK signal pathway $(15,16)$, including the p38 MAPK and extracellular signal-regulated kinase $1 / 2$ (Erk 1/2) MAPK signaling. MAPK pathway is critically involved in the regulation of the synthesis of inflammation mediators (17). Increased concentrations of inflammatory cytokines, tumor necrosis factor- $\alpha$ (TNF- $\alpha$ ) and interleukin-6 (IL-6), are observed in many inflammatory disorders, which also contribute to the progression of podocyte injury $(18,19)$. Although TGF- $\beta$ has been shown to play an essential role in the suppression of inflammation, other studies have also revealed the positive roles of TGF- $\beta$ in inflammatory responses (20). Based on the aforementioned facts, and the known interaction of TGF- $\beta$ and MAPK pathways in cancer progression (21), it was proposed that the mechanisms of miR-155 in regulating TGF- $\beta$-induced podocyte injury were associated with podocyte inflammation and MAPK signaling.

Therefore, in the present study, the diagnostic value of miR-155 levels in EGD was first studied. The mRNA and protein expression of synaptopodin and CD2AP, the miR-155 expression and inflammatory cytokine production were measured in the in vitro model of TGF- $\beta 1$-induced podocyte injury using mouse podocyte cells treated with different doses of TGF- $\beta 1$ for different periods. Importantly, the present study explored the association between miR-155 expression and activation of MAPK signaling pathway and the production of proinflammatory mediators to reveal the potential mechanisms of miR-155 in regulating podocyte injury.

\section{Materials and methods}

Patient characteristics. A total of 60 patients with primary nephrotic syndrome (PNS) (42 males and 18 females) aged 11-62 years (mean, $37.75 \pm 16.81$ years) with a body mass index (BMI) in the range of $17.25-26.76 \mathrm{~kg} / \mathrm{m}^{2}$ (average, $21.25 \pm 2.20 \mathrm{~kg} / \mathrm{m}^{2}$ ) were selected for the first hospitalization.
Of these, 22 patients had nephropathy, 36 patients had membranous nephropathy, and 22 patients had focal segmental glomerulosclerosis.

In addition, 60 healthy individuals (40 males and 20 females) aged 12-61 years (mean, $38.65 \pm 13.02$ years) with a BMI of $18.53-26.45 \mathrm{~kg} / \mathrm{m}^{2}$ (average, $22.55 \pm 2.51 \mathrm{~kg} / \mathrm{m}^{2}$ ) were randomly selected as the control group, who received physical examination during the same period.

Urine sediment extraction. Urine specimens from patients at early stage of glomerular disease (including minimal change nephropathy, membranous nephropathy and segmental glomerulosclerosis) and healthy controls from March 2019 to March 2020 were collected at the Affiliated Hospital of Youjiang Medical University for Nationalities (BaiSe, China). All patients were kept off foods and beverages for at least $8 \mathrm{~h}$, and $30 \mathrm{ml}$ mid-stream urine specimen from the first morning void was collected in a $50-\mathrm{ml}$ centrifuge tube. After centrifugation of urine samples at $3,000 \mathrm{x}$ g for 5 to $10 \mathrm{~min}$ at $4^{\circ} \mathrm{C}$, the supernatant was discarded. Next, after centrifugation at $14,000 \mathrm{x} \mathrm{g}$ for $5 \mathrm{~min}$ at $4^{\circ} \mathrm{C}$, invalid supernatant was wiped off and the urine deposition was collected. All the participants provided informed consent in writing. This study was approved by the ethical committee of the Youjiang Medical University for Nationalities.

Cell culture. Conditionally immortalized mouse podocytes were purchased from the cell center of Fudan University (Shanghai, China). These podocyte cells were then cultured and treated as previously reported (22). Briefly, mouse podocyte cells were cultured at $33^{\circ} \mathrm{C}$ and expanded in RPMI-1640 (Gibco; Thermo Fisher Scientific, Inc.) containing 10\% fetal bovine serum (FBS; Cellmax) and $10 \mathrm{U} / \mathrm{ml}$ recombinant mouse $\gamma$-interferon (cat. no. PMC4031; Invitrogen; Thermo Fisher Scientific, Inc.). Podocyte cells began to differentiate when incubated at $37^{\circ} \mathrm{C}$ and were cultured without $\gamma$-interferon. When podocytes reached to $\sim 80 \%$ confluence, they were treated with TGF- $\beta 1$ (cat no. 90-100-21-2; PeproTech, Inc.) at indicated doses or durations in a serum-free medium.

Podocyte treatment. Podocyte cells were seeded into six-well plates at a density of $1 \times 10^{6} \mathrm{ml}^{-1}$ and treated with TGF- $\beta 1$ at different doses $(4,8$ and $12 \mathrm{ng} / \mathrm{ml})$ or with $12 \mathrm{ng} / \mathrm{ml} \mathrm{TGF}-\beta 1$ for different durations $(24,48$ and $72 \mathrm{~h})$. For the inhibition of p38 MAPK or Erk 1/2 MAPK, the differentiated podocytes were incubated with $25 \mu \mathrm{M}$ SB203580 (S1076; Selleck Chemicals) or $25 \mu \mathrm{M}$ U0126-EtOH (S1102; Selleck Chemicals), respectively.

Enzyme-linked immunosorbent assay (ELISA). The supernatants were collected from cell cultures at the indicated time, and the concentrations of TNF- $\alpha$ and IL- 6 were assayed using TNF- $\alpha$ ELISA kit (cat. no. CSB-E04741m; Mouse TNF- $\alpha$ ELISA kit; Cusabio Biotech) and IL-6 ELISA kit (cat. no. CSB-E04639m; Mouse IL-6 ELISA kit; Cusabio Biotech), according to the manufacturer's instructions.

Reverse transcription-quantitative polymerase chain reaction (RT-qPCR). Total RNA was extracted from the cells using the RNAiso Plus kit (cat. no. 9108; Takara Bio, Inc.). 
The Mir-X miRNA First-Strand Synthesis kit (cat. no. 638315; Clontech Laboratories, Inc.) and PrimeScript ${ }^{\mathrm{TM}}$ RT reagent kit (cat. no. RR047A; Takara Bio, Inc.) were used for reverse transcription of miRNA and mRNA molecules into respective cDNA templates. The miRNA reverse transcription was performed at $37^{\circ} \mathrm{C}$ for $1 \mathrm{~h}$, then $85^{\circ} \mathrm{C}$ for $5 \mathrm{~min}$. The mRNA reverse transcription was performed at $37^{\circ} \mathrm{C}$ for $15 \mathrm{~min}$, then $85^{\circ} \mathrm{C}$ for $5 \mathrm{sec}$. Real-time amplification was performed using SYBR ${ }^{\circledR}$ Premix Ex Taq ${ }^{\mathrm{TM}}$ II (Tli RNaseH Plus; cat. no. RR820A; Takara Bio, Inc.). All primers were obtained from Takara Bio, Inc., and the sequences are listed in Table I. The reaction system was composed of $0.8 \mu \mathrm{l}$ forward and reverse primers (concentration of $10 \mu \mathrm{mol} / 1$ each), $2 \mu \mathrm{l} \mathrm{cDNA}$ template, $10 \mu 1$ X2 SYBR-Green qPCR mix, and $6.4 \mu$ 1 double distilled water. The PCR reaction protocol consisted of two steps: Step 1, initial denaturation for $30 \mathrm{sec}$ at $95^{\circ} \mathrm{C}$; and Step 2, denaturation for $5 \mathrm{sec}$ at $95^{\circ} \mathrm{C}$, annealing and extension for $20 \mathrm{sec}$ at $62^{\circ} \mathrm{C}$, and fluorescence signal acquisition. The data were collected using LightCycler ${ }^{\circledR} 96$ (Roche Diagnostics). U6 and GAPDH were regarded as the internal reference of miRNA and mRNA, respectively. The $2^{-\Delta \Delta C q}$ method was used to determine the relative expression of the target genes (23).

Western blotting. The total protein was extracted from cells using the radioimmunoprecipitation assay buffer containing protease and phosphatase inhibitor cocktail (CWBIO). The concentration of total protein was determined using the bicinchoninic acid (BCA) method; $50 \mu \mathrm{g}$ total protein was loaded to run $8 \%$ sodium dodecyl sulfate-polyacrylamide gel electrophoresis. Then, the protein was transferred onto polyvinylidene fluoride membranes (cat. no. IPVH000101; EMD Millipore). The membranes were blocked by Tris-buffered saline with $0.05 \%$ Tween-20 (TBST) composed of $5 \%$ non-fat milk powder for $1 \mathrm{~h}$ at $4{ }^{\circ} \mathrm{C}$. Subsequently, the membranes were incubated with the antibodies, including rabbit anti-CD2AP (cat. no. 51046-1-AP; ProteinTech Group, Inc.) at 1:500 dilution; synaptopodin (cat. no. 21064-1-AP; ProteinTech Group, Inc.) at 1:500 dilution; CD2AP (cat. no. 51046-1-AP; ProteinTech Group, Inc.) at 1:500 dilution; phosphorylated (p)-p38 [Thr180/Tyr182 (clone D3F9); cat. no. 4511; Cell Signaling Technology, Inc. (CST)] at 1:1,000 dilution; p38 (cat. no. 9212; CST) at 1:1,000 dilution; p-Erk [Thr202/Tyr204 (clone D13.14.4E), cat. no. 4370, CST] at 1:2,000 dilution; Erk 1/2 (cat. no. 9102; CST) at 1:1,000 dilution, and GAPDH (cat. no. 10494-1-AP; ProteinTech Group, Inc.) at 1:5,000 dilution at $4^{\circ} \mathrm{C}$ overnight. After washing, the horseradish peroxidase (HRP)-conjugated affinity-purified goat anti-rabbit IgG (H + L) (cat. no. SA00001-2; ProteinTech Group, Inc.) was used for hybridization at room temperature for $1 \mathrm{~h}$, followed by autoradiograph. Chemiluminescence assay kit (cat. no. P0018S; Beyotime Institute of Biotechnology) was used visualize the protein bands in a ChemiDoc Imaging System (Bio-Rad Laboratories, Inc.). The band intensities were quantified by densitometry using the ImageJ software (version 1.49; National Institutes of Health).

Statistical analysis. The SPSS 17.0 software (SPSS, Inc.) and GraphPad software (GraphPad Software, Inc.) were used for all statistical analyses. The test data of each sample accorded with the normal distribution through plentiful repeated experiments
Table I. Sequences of primers used in the present study.

Gene Primer sequences

Synaptopodin F: 5'-GCTCGAATTCCGATGCAAATAAAC-3' R: 5'-CAGGCCACAGTGAGATGTGAAGA-3'

CD2AP F: 5'-AGGAATTCAGCCACATCCACA-3' R: 5'-CGATCAATTCCAGTTCGTCCTC-3'

GAPDH F: 5'-TGTGTCCGTCGTGGATCTGA-3' R: 5'-TTGCTGTTGAAGTCGCAGGAG-3'

Primers for quantifying miR-155 levels were purchased from Takara Bio, Inc., and have been patented. Therefore, no sequence information was provided. Primers for quantifying U6 levels were supplied by the Mir-X miRNA First-Strand Synthesis Kit and no sequence information was provided. F, forward; R, reverse.

and statistical analyses. Measurement data are represented as mean \pm standard deviation, and the experiments were repeated three times. Comparisons between the two groups were examined using the t-test. Comparison among more than two groups was analyzed by one-way analysis of variance (ANOVA); LSD test was used when analyzing 3 groups, Tukey's test was used when analyzing 4 or more groups, and the missing variance was analyzed using Games-Howell test. The Pearson correlation was used to analyze the correlation between the levels of miR-155 and several pro-inflammatory cytokines. Receiver operating characteristic (ROC) curves were plotted, and the area under the ROC curve (AUC) was calculated to assess the specificity and sensitivity of predicting patients with EGD and controls by the expression levels of miR-155 in the urine specimens. The $\chi^{2}$ test was used to analyze the association between miR-155 expression and clinicopathological characteristics. $\mathrm{P}<0.05$ was considered to indicate a statistically significant difference.

\section{Results}

miR-155 expression in the urine of patients with EGD is significantly higher compared with that of healthy controls. In the present study, the abundance of miR-155 in urine specimens collected from patients was compared with healthy controls in order to explore the possible involvement of miR-155 in the pathogenesis of EGD. The results of RT-qPCR showed that the expression levels of miR-155 from patients with podocyte injury at the early stage of glomerular disease were nearly 4.5 -fold of that from the normal control group, and the difference was statistically significant $(\mathrm{P}<0.05$; Fig. 1A). The diagnostic value of miR-155 was also explored using ROC analysis. As shown in Fig. 1B, the AUC was 0.9548, and the sensitivity and specificity of using the miR-155 level as a parameter to diagnose podocyte injury in EGD was 93.27 and $92.58 \%$, respectively, which confirmed that miR-155 is a good biomarker for the diagnosis of podocyte injury in humans. The association between miR-155 expression and clinicopathological characteristics is shown in Table II, which showed no significant association between miR-155 expression and clinicopathological characteristics. 
A

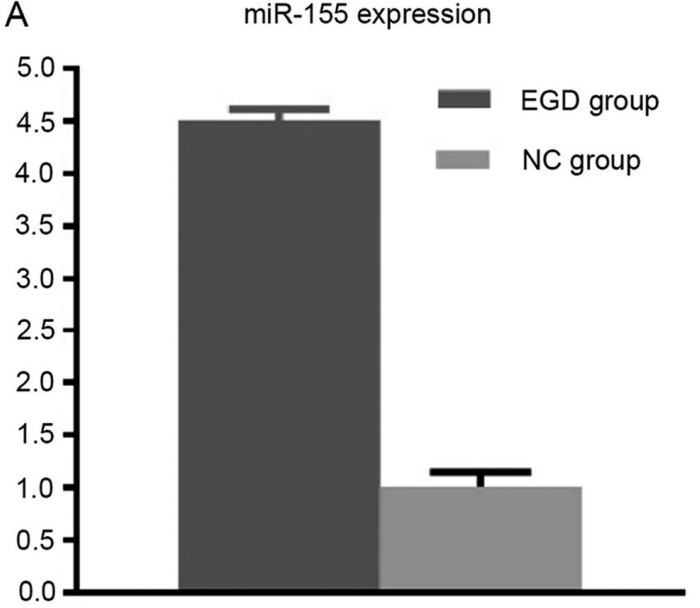

B

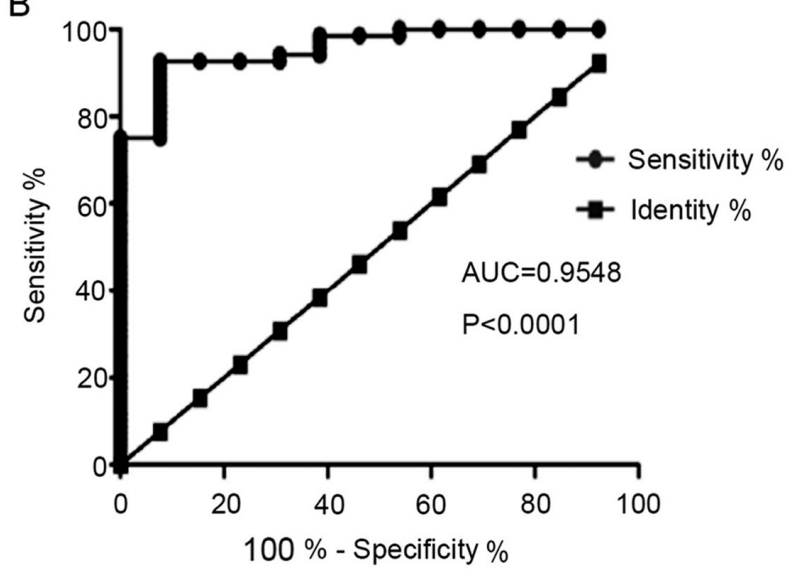

Figure 1. miR-155 expression levels in urine samples to diagnose podocyte injury at the early stage of glomerular disease. (A) Comparison of miR-155 expression in urine samples from patients with EGD and NCs; $n=60$ for EGD and NC groups. (B) Evaluation of the values of miR-155 as a diagnostic biomarker of podocyte injury in EGD using the receiver operating characteristics curve. The abscissa axis was for false positive rate (1-specificity) and the ordinate axis was for true positive rate (sensitivity). miR, microRNA; EGD, early glomerular disease; NC, normal controls; AUC, area under the curve.

A

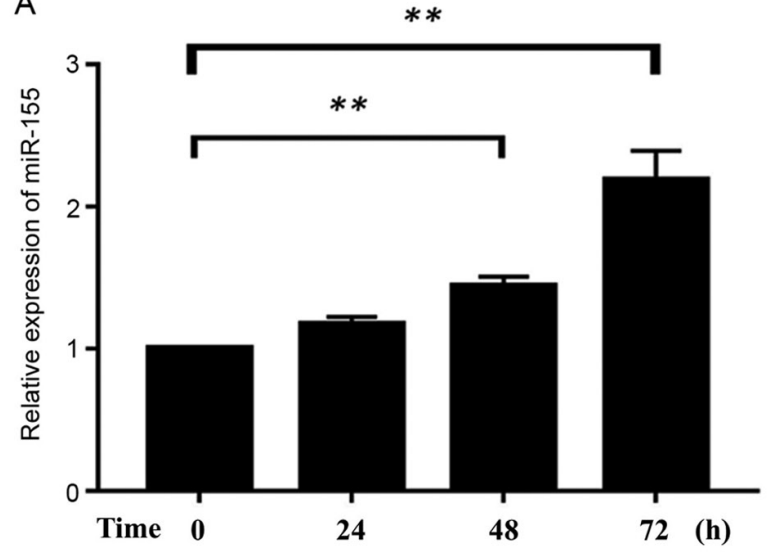

B

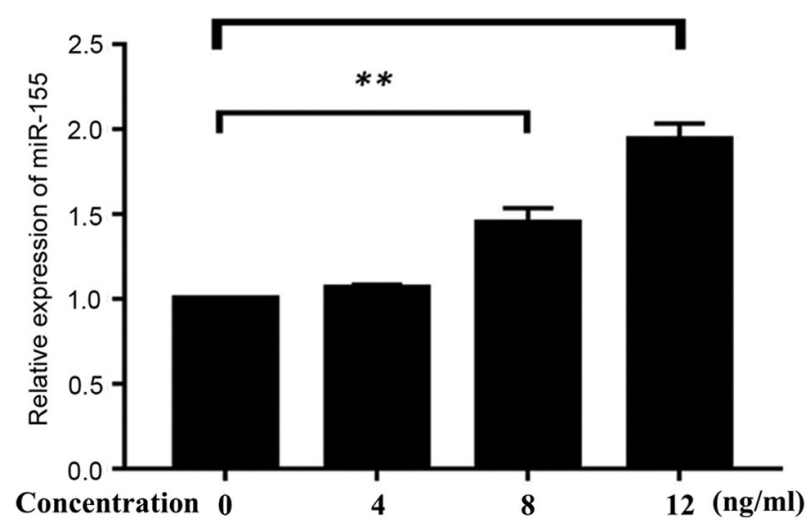

Figure 2. Induction of dose- and time-dependent miR-155 expression by TGF- $\beta 1$ in mouse podocyte cells. (A) The levels of miR-155 expression in podocytes treated with $12 \mathrm{ng} / \mathrm{ml}$ TGF- $\beta 1$ for the indicated durations (24, 48 and $72 \mathrm{~h}$ ) were measured by RT-qPCR. (B) The levels of miR-155 expression in podocytes treated with different concentrations $(4,8$ and $12 \mathrm{ng} / \mathrm{ml})$ of TGF- $\beta 1$ for $72 \mathrm{~h}$ were measured by RT-qPCR. All data are presented as mean \pm SD of three independent experiments. ${ }^{*} \mathrm{P}<0.05 ;{ }^{* *} \mathrm{P}<0.01$. miR, microRNA; TGF, transforming growth factor; RT-qPCR, reverse transcription-quantitative PCR.

Table II. Association between miR-155 expression and clinicopathological characteristics.

\begin{tabular}{lccc}
\hline Characteristic & $\begin{array}{c}\text { Low miR-155 } \\
\text { group (n=60) }\end{array}$ & $\begin{array}{c}\text { High miR-155 } \\
\text { group (n=60) }\end{array}$ & P-value \\
\hline Sex & & & 0.845 \\
$\quad$ Male & 40 & 42 & \\
$\quad$ Female & 20 & 18 & \\
Age & & & 0.709 \\
$<35$ years & 38 & 35 & \\
$>35$ years & 22 & 25 & \\
BMI & & & 0.361 \\
$<24 \mathrm{~kg} / \mathrm{m}^{2}$ & 28 & 34 & \\
$>24 \mathrm{~kg} / \mathrm{m}^{2}$ & 32 & 26 & \\
\hline
\end{tabular}

miR, microRNA; BMI, body mass index.
TGF- $\beta 1$-induced miR-155 expression in a dose-and time-dependent manner in mouse podocyte cells. Based on previous observation of the differentially expressed miR-155 in nephropathy mice and control mice (14), the effects of in vitro TGF- $\beta 1$ treatments on miR-155 expression were further explored in mouse podocyte cells. Podocytes were treated with TGF- $\beta 1$ at different doses and for different durations, and the expression levels of miR-155 in the TGF- $\beta 1$ intervention groups and control groups were examined using RT-qPCR. As anticipated, miR-155 expression level was significantly higher in the TGF- $\beta 1$ intervention groups. Specifically, when cells were treated with $12 \mathrm{ng} / \mathrm{ml}$ TGF- $\beta 1$, miR- 155 expression of the intervention groups gradually increased with time (Fig. 2A). When cells were treated for $72 \mathrm{~h}$, miR-155 expression of the intervention groups gradually increased with the increase in TGF- $\beta 1$ concentrations (Fig. 2B).

Dose- and time-dependent downregulation of synaptopodin and CD2AP expression levels by TGF- $\beta 1$ in mouse podocyte 

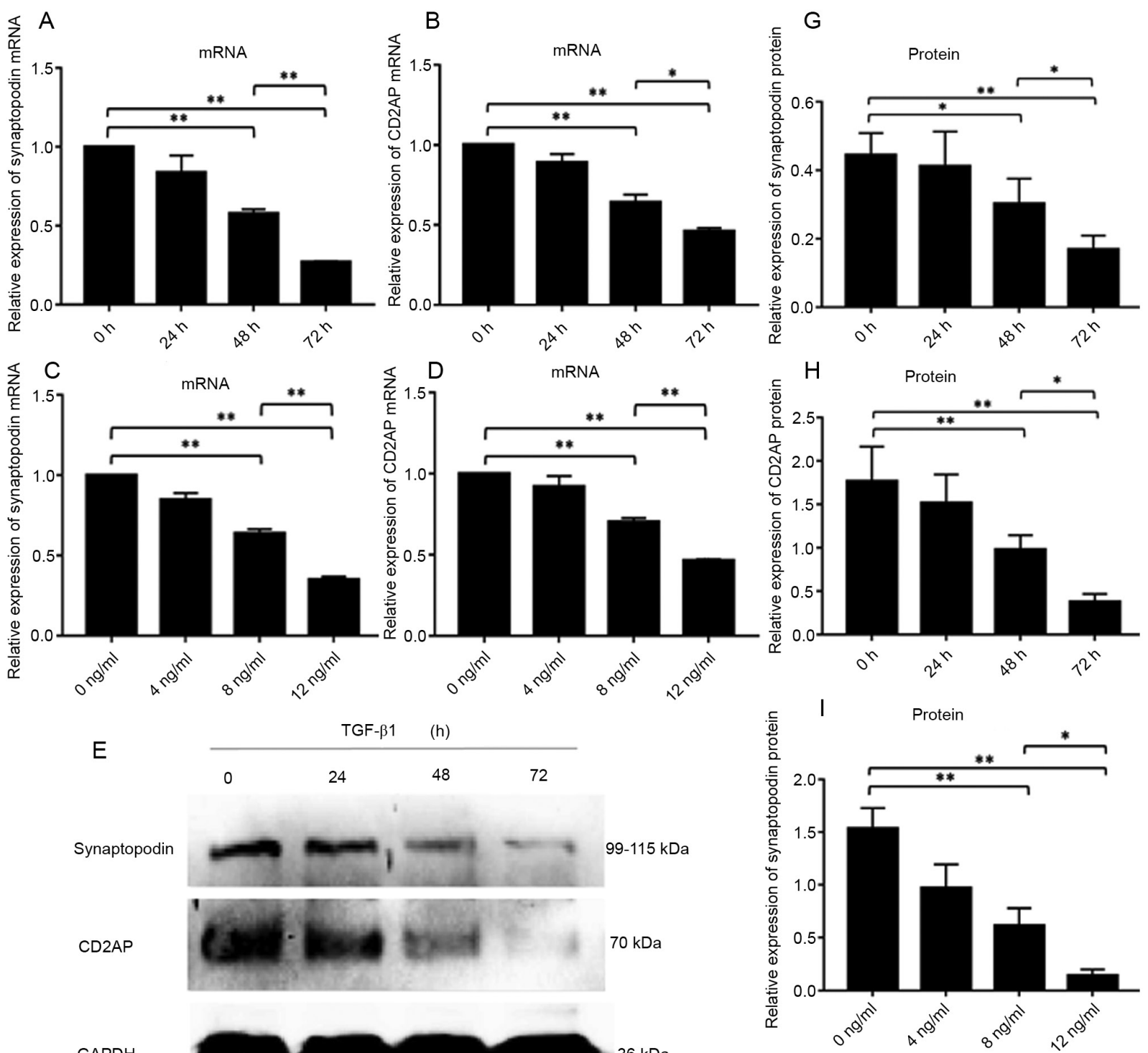

GAPDH

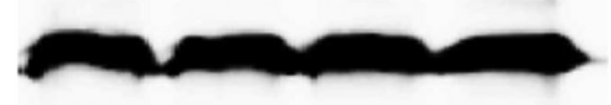

$36 \mathrm{kDa}$
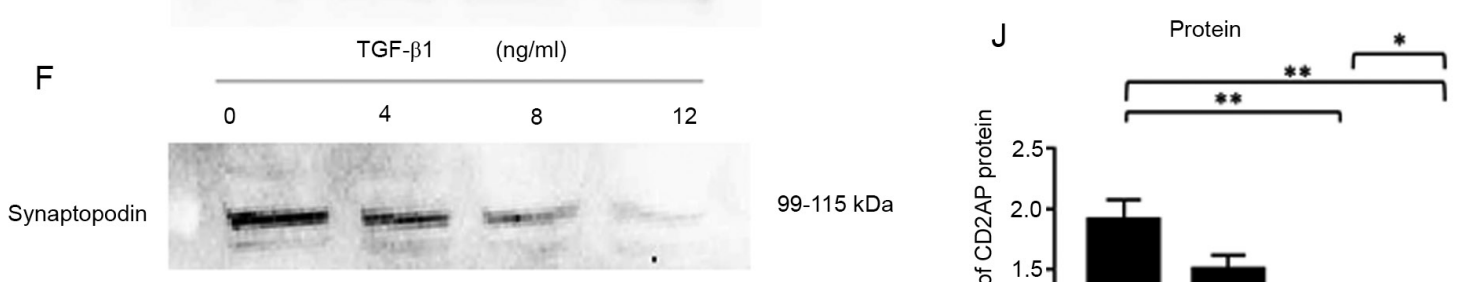

CD2AP

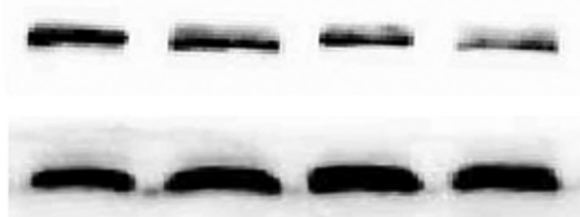

70 kDa

$36 \mathrm{kDa}$

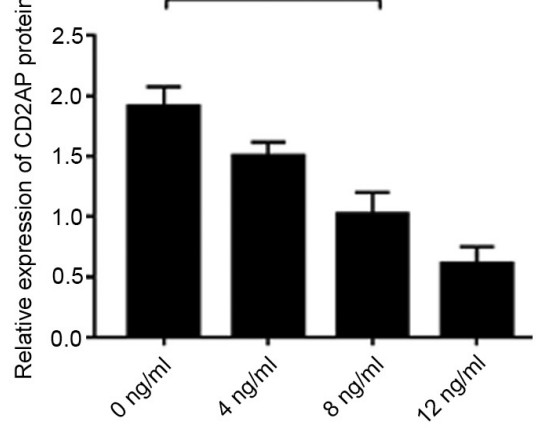

Figure 3. Effects of TGF- $\beta 1$ treatments on the expression levels of synaptopodin and CD2AP in mouse podocytes. The mRNA expression of synaptopodin and CD2AP in podocytes treated with $12 \mathrm{ng} / \mathrm{ml}$ TGF- $\beta 1$ at the indicated durations (A and B) or treated with the indicated doses of TGF- $\beta 1$ for $72 \mathrm{~h}(\mathrm{C}$ and $\mathrm{D}$ ) were evaluated using reverse transcription-quantitative PCR. Western blotting was performed to determine the relative expression levels of synaptopodin and CD2AP proteins in podocytes treated with $12 \mathrm{ng} / \mathrm{ml}$ TGF- $\beta 1$ for the indicated periods (E and G-H) or treated with TGF- $\beta 1$ at the indicated doses for $72 \mathrm{~h}$ (F and I-J). The levels of GAPDH are shown as loading control. All data are presented as mean $\pm \mathrm{SD}$ of three independent experiments. $\mathrm{P}<0.05$; ${ }^{* *} \mathrm{P}<0.01$. TGF, transforming growth factor; CD2AP, CD2-associated protein.

cells. RT-qPCR and western blot analyses were performed to determine the mRNA (Fig. 3A-D) and protein (Fig. 3E-J) expression levels of synaptopodin and CD2AP in the TGF- $\beta 1$ intervention and the control groups. These analyses helped in determining the severity of TGF- $\beta 1$-induced podocyte injury. Compared with the control group, all of the intervention groups 

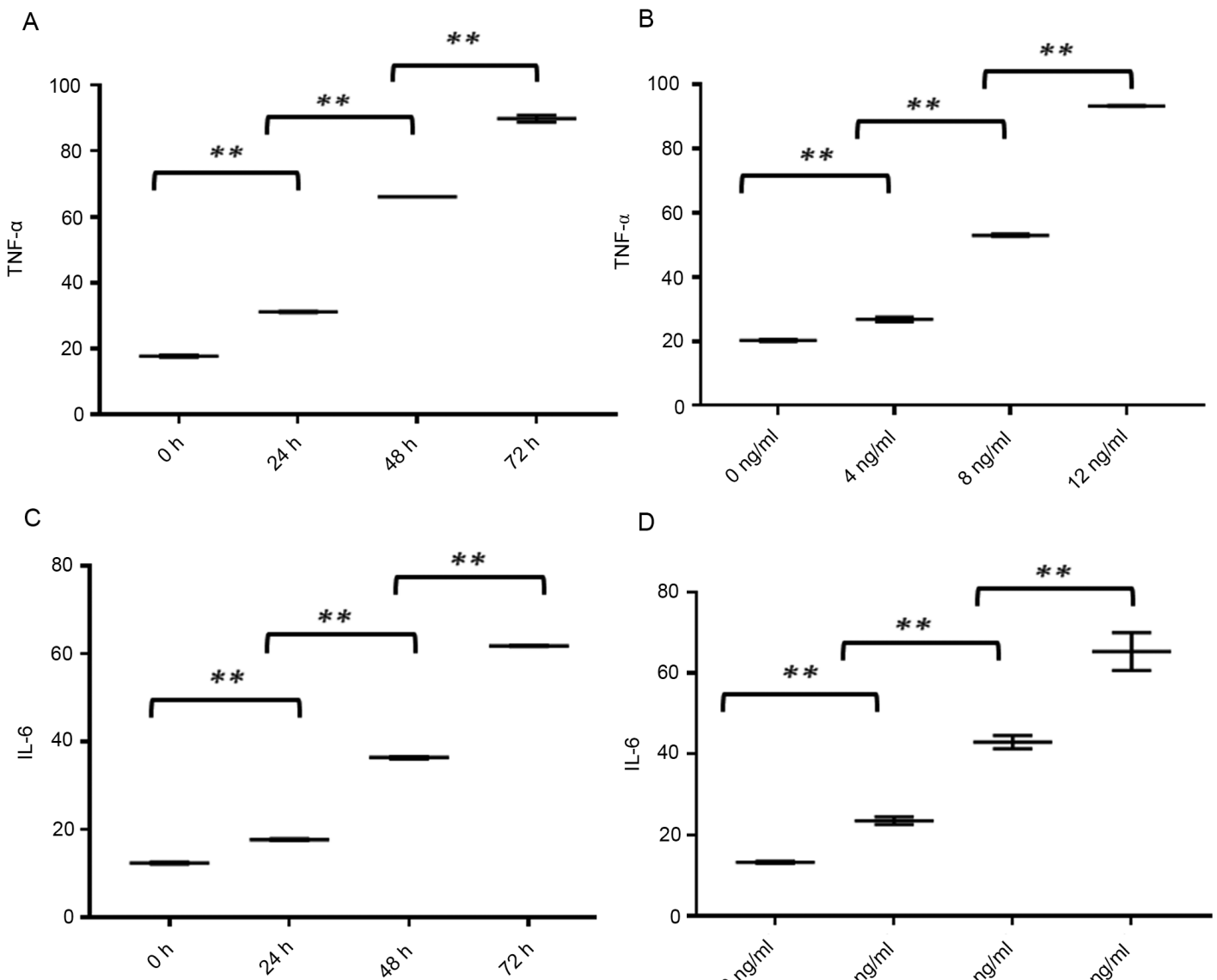

D

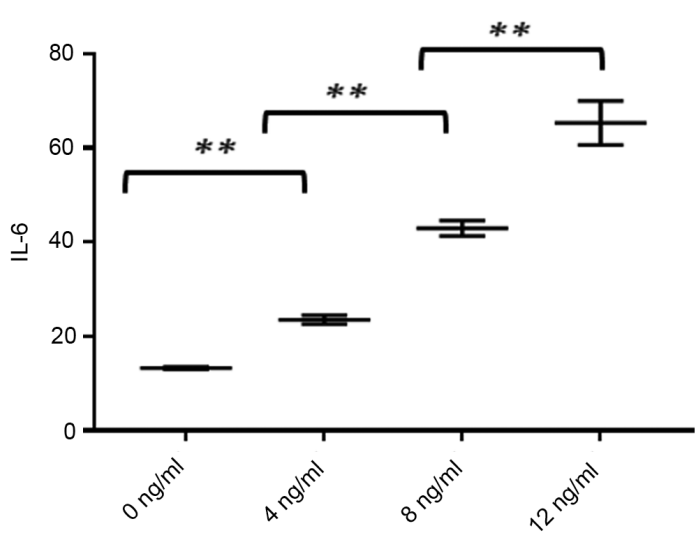

Figure 4. Dose- and time-dependent TGF- $\beta 1$-induced production of TNF- $\alpha$ and IL-6 in mouse podocyte cells. (A-D) Enzyme-linked immunosorbent assays were performed to determine the relative levels of soluble TNF- $\alpha$ (A and B) and IL-6 (C and D) in culture supernatants of podocytes treated with $12 \mathrm{ng} / \mathrm{ml}$ TGF- $\beta 1$ for the indicated periods (A and C) or treated with TGF- $\beta 1$ at the indicated doses for $72 \mathrm{~h}(\mathrm{~B}$ and $\mathrm{D})$. All data are presented as mean \pm SD of three independent experiments. ${ }^{* *} \mathrm{P}<0.01$. TGF, transforming growth factor; TNF- $\alpha$, tumor necrosis factor- $\alpha$; IL- 6 , interleukin- 6 .

had decreased mRNA expression levels of synaptopodin and CD2AP (Fig. 3A-D), and the decrease appeared to be dependent on the time and dose of TGF- $\beta 1$ treatment. Similarly, with the increase in the dose and duration of TGF- $\beta 1$ treatment, the protein expression levels of synaptopodin and CD2AP were also gradually decreased and reached the lowest levels at the dose of $12 \mathrm{ng} / \mathrm{ml}$ TGF- $\beta 1$ at the duration of $72 \mathrm{~h}$ (Fig. 3E-J).

Association between TGF- $\beta 1$-induced release of pro-inflammatory cytokines and elevation of miR-155 expression in mouse podocytes. In the present study, ELISA assay was performed to evaluate the levels of TNF- $\alpha$ and IL- 6 from TGF- $\beta 1$-treated cells, exploring the inflammatory effects of TGF- $\beta 1$ on podocyte cells. Results showed that the expression levels of TNF- $\alpha$ (Fig. 4A and B) and IL-6 (Fig. 4C and D) in cell culture supernatants were both obviously increased by the treatment with TGF- $\beta 1(\mathrm{P}<0.01)$ compared with the control groups. Notably, the secretion of these cytokines increased in a time- and dose-dependent manner, which indicated that the production of inflammatory cytokines was closely associated with TGF- $\beta 1$-induced podocyte injury. TGF- $\beta 1$ intervention upregulated miR-155 expression in podocytes (Fig. 2). Further, Pearson's correlation analysis demonstrated that miR-155 expression levels and the levels of soluble TNF- $\alpha$ (Fig. 5A and B) or IL-6 (Fig. 5C and D) in cell culture supernatants had significantly positive correlations
$(\mathrm{P}<0.01)$ in podocytes treated with different doses of TGF- $\beta 1$ for $72 \mathrm{~h}$ or $12 \mathrm{ng} / \mathrm{ml} \mathrm{TGF}-\beta 1$ for different durations. Therefore, TGF- $\beta 1$-induced podocyte injury can lead to a series of inflammation and accompanying elevation of miR-155 expression.

TGF- $\beta 1$-induced activation of p38 and Erk $1 / 2$ pathways in the process of podocyte injury. A previous study demonstrated that activated MAPK signaling pathways, such as p38 and Erk 1/2, are crucial for the differentiation, proliferation and apoptosis of podocytes (24). The present study investigated whether p38 and Erk 1/2 pathways were involved in the process of TGF- $\beta 1$-induced podocyte injury. The expression levels of p38, p-p38, Erk 1/2 and p-Erk 1/2 in podocytes at different time points after $12-\mathrm{ng} / \mathrm{ml}$ TGF- $\beta 1$ intervention were examined by western blot assays. As shown in Fig. 6A, both p-p38 and $\mathrm{p}$-Erk 1/2 expression levels were significantly upregulated after TGF- $\beta 1$ stimulation. The level of p-p38 expression significantly increased at $30 \mathrm{~min}(\mathrm{P}<0.01)$, and was maintained at a high level even at $1 \mathrm{~h}$ after TGF- $\beta 1$ treatment (Fig. 6B). Similarly, compared with the control group, p-Erk 1/2 expression increased significantly at $15 \mathrm{~min}(\mathrm{P}<0.01)$, and reached a peak level at $30 \mathrm{~min}$ (Fig. 6C).

Attenuation of TGF- $\beta 1$-induced podocyte injury due to inactivation of $p 38$ and Erk 1/2 pathways. The aforementioned results demonstrated that TGF- $\beta 1$ activates the MAPK 

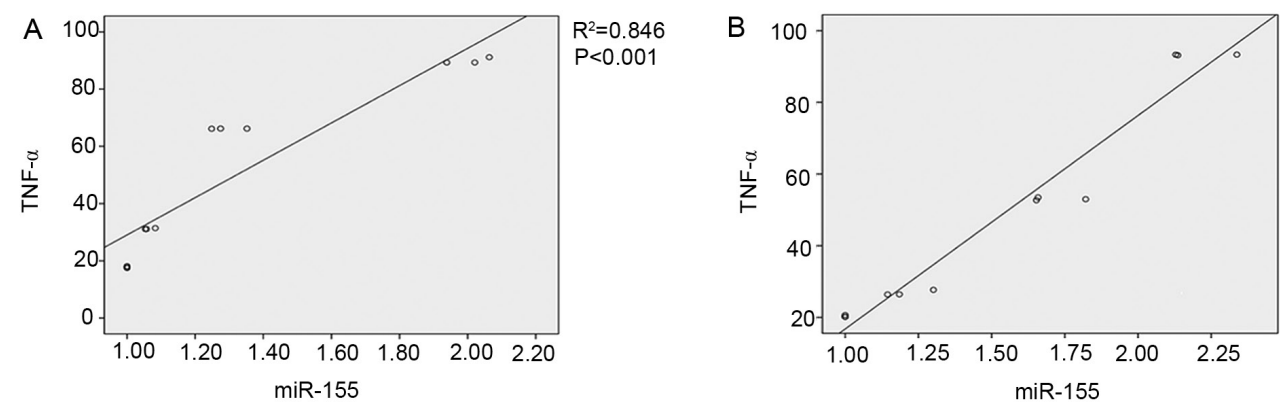

$\mathrm{R}^{2}=0.955$
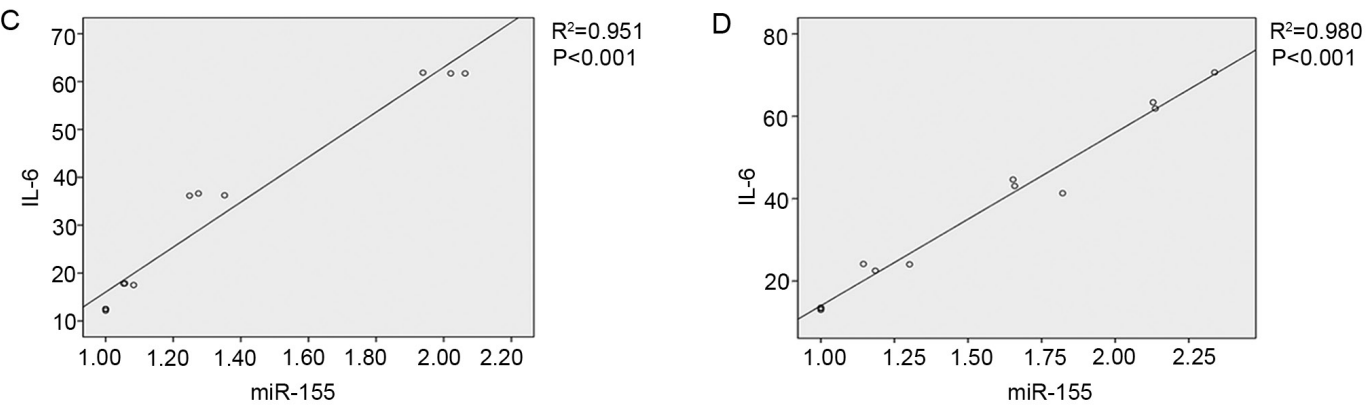

Figure 5. TGF- $\beta 1$-induced release of pro-inflammatory cytokines correlated with the elevation of miR-155 expression in mouse podocytes. The correlation between TNF- $\alpha$ levels in culture supernatants of podocytes treated with $12 \mathrm{ng} / \mathrm{ml}$ TGF- $\beta 1$ for the indicated periods (A) or treated with TGF- $\beta 1$ at the indicated doses for $72 \mathrm{~h}$ (B); the corresponding miR-155 expression were analyzed using Pearson's correlation. The correlation between IL-6 levels in culture supernatants of podocytes treated with $12 \mathrm{ng} / \mathrm{ml}$ TGF- $\beta 1$ for the indicated periods (C) or treated with TGF- $\beta 1$ at the indicated doses for $72 \mathrm{~h}$ (D); the corresponding miR-155 expression were analyzed using Pearson's correlation. TGF, transforming growth factor; miR, microRNA.

A

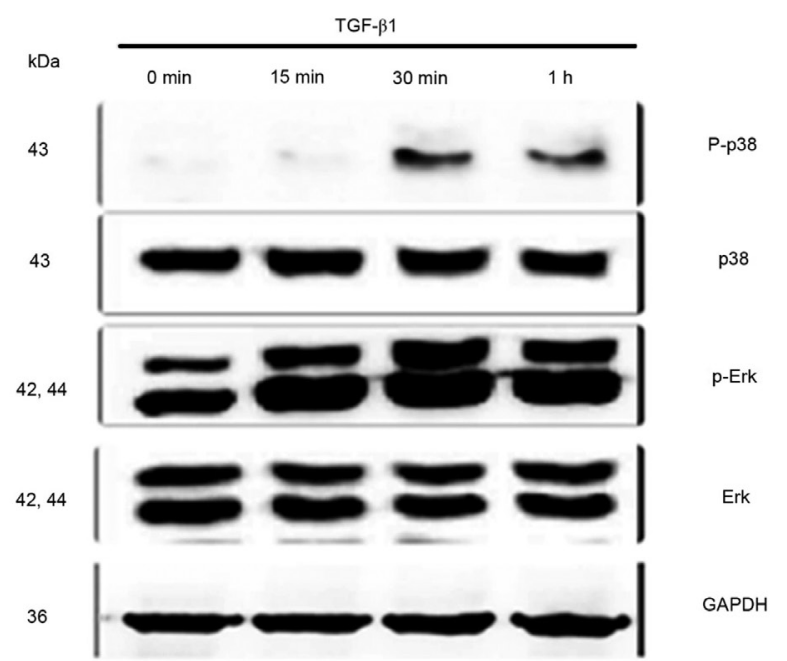

B

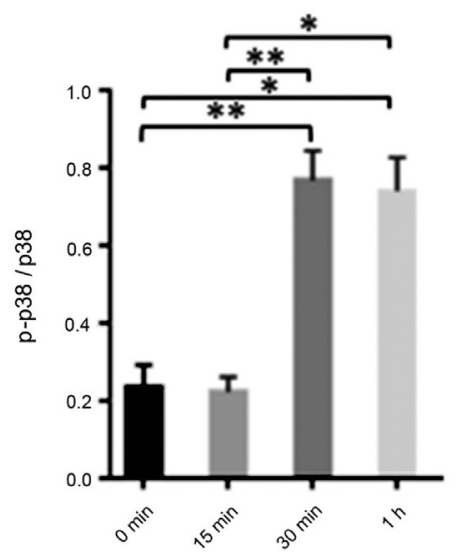

C

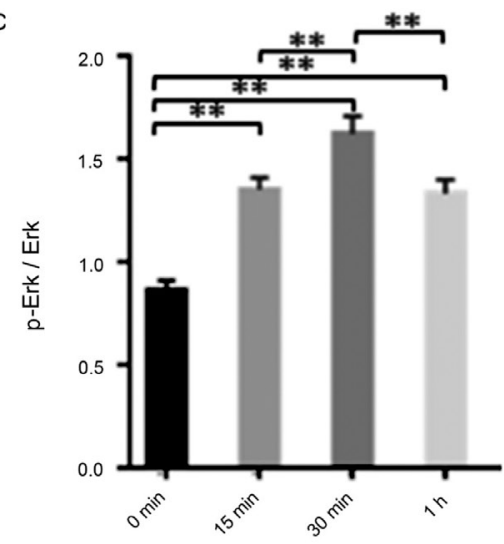

Figure 6. TGF- $\beta 1$ treatment-activated MAPK signaling during the process of podocyte injury. Western blotting was performed to determine the levels of p-p38, total p38, p-Erk 1/2, total Erk 1/2 and GAPDH in mouse podocytes treated with $12 \mathrm{ng} / \mathrm{ml}$ TGF- $\beta 1$ for the indicated time periods. Total Erk, total p38 and GAPDH served as loading controls. Representative images of blot bands are shown (A), and the ratios of p-p38 to p38 (B) and p-Erk 1/2 to Erk 1/2 (C) are summarized. All data are presented as mean $\pm \mathrm{SD}$ of three independent experiments. ${ }^{*} \mathrm{P}<0.05,{ }^{* * *} \mathrm{P}<0.01$. TGF, transforming growth factor; $\mathrm{p}$ - phosphorylated. 

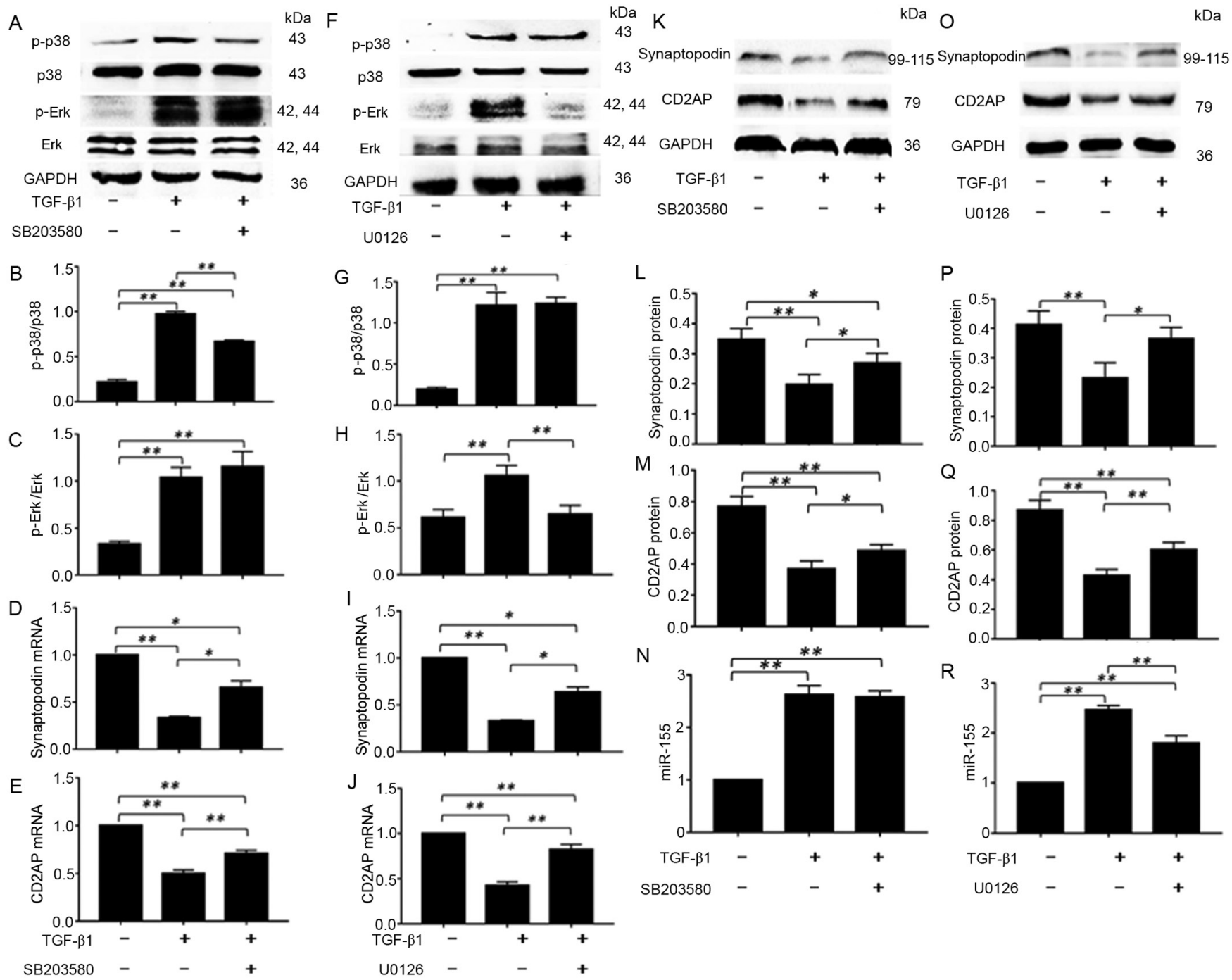

L
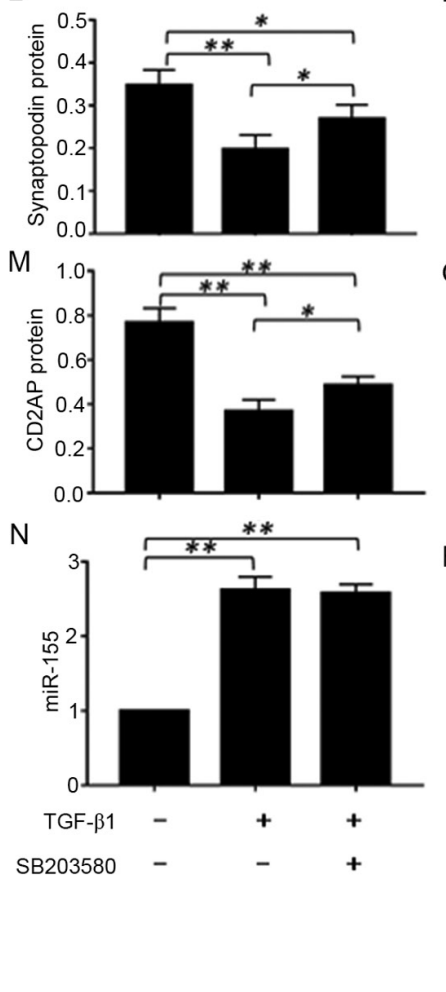

$P$

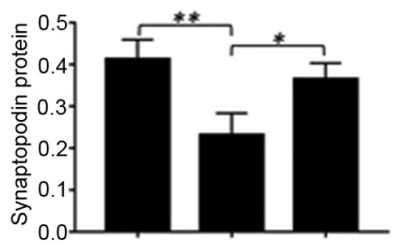

Q

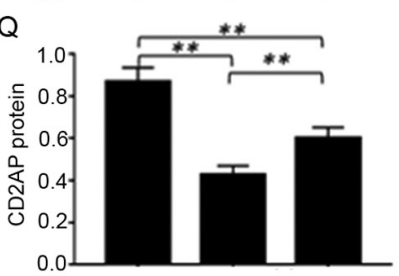

$\mathrm{R}$

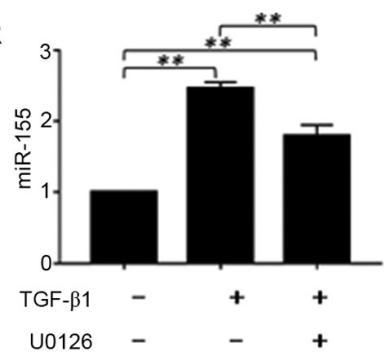

Figure 7. Attenuation of TGF- $\beta 1$-induced podocyte injury and decrease in miR-155 expression due to the inactivation of MAPK signaling. Mouse podocyte cells were left untreated or treated with $12 \mathrm{ng} / \mathrm{ml} \mathrm{TGF}-\beta 1$ alone, or together with $25 \mu \mathrm{M} \mathrm{SB} 203580$ for $1 \mathrm{~h}$. The protein levels of p-p38, p38, p-Erk 1/2, Erk 1/2 and GAPDH were measured using western blotting (A-C), while the mRNA levels of synaptopodin (D) and CD2AP (E) were measured using RT-qPCR Mouse podocyte cells were left untreated or treated with $12 \mathrm{ng} / \mathrm{ml}$ TGF- $\beta 1$ alone, or together with $25 \mu \mathrm{M}$ U0126 for $1 \mathrm{~h}$. The protein levels of p-p38, p38, p-Erk 1/2, Erk 1/2, and GAPDH were measured using western blotting (F-H), while the mRNA levels of synaptopodin (I) and CD2AP (J) were measured using RT-qPCR. (K-N) Mouse podocyte cells were left untreated or treated with $12 \mathrm{ng} / \mathrm{ml}$ TGF- $\beta 1$ alone, or together with $25 \mu \mathrm{M} \mathrm{SB} 203580$ for $72 \mathrm{~h}$. The protein levels of synaptopodin (L), CD2AP (M) and GAPDH were measured using western blotting (K-M), while the transcription level of miR-155 (N) was measured using RT-qPCR. (O-R) Mouse podocyte cells were left untreated or treated with $12 \mathrm{ng} / \mathrm{ml} \mathrm{TGF}$ - $\beta 1$ alone, or together with $25 \mu \mathrm{M} \mathrm{U} 0126$ for $72 \mathrm{~h}$. The protein levels of synaptopodin $(\mathrm{P}), \mathrm{CD} 2 \mathrm{AP}(\mathrm{Q})$ and GAPDH were measured using western blotting $(\mathrm{O}-\mathrm{Q})$, while the transcription level of miR-155 (R) was measured using RT-qPCR. All data are presented as mean $\pm \mathrm{SD}$ of three independent experiments. ${ }^{*} \mathrm{P}<0.05 ;{ }^{* *} \mathrm{P}<0.01$. TGF, transforming growth factor; miR, microRNA; p-, phosphorylated; RT-qPCR, reverse transcription-quantitative PCR; CD2AP, CD2-associated protein

signal pathways in mouse podocytes. Therefore, the present study tested whether the MAPK signaling was required for TGF- $\beta 1$-induced podocyte injury, by treating the cells with specific inhibitors. The differentiated mouse podocytes were treated with TGF- $\beta 1$ in the absence or presence of SB203580, an inhibitor of p38 MAPK activity. The results showed that SB203580 successfully prevented the phosphorylation of p38 $(\mathrm{P}<0.01)$, while the expression of $\mathrm{p}$-Erk $1 / 2$ remained unchanged (Fig. 7A-C). Similarly, podocytes treated with U0126, an inhibitor of the MEK activity, inhibited the phospho-Erk $1 / 2$ expression $(\mathrm{P}<0.01)$, but did not change the phosphorylation degree of p38 (Fig. 7F-H). Notably, compared with the control group, the expression levels of synaptopodin and CD2AP significantly decreased in the TGF- $\beta 1$-alone group $(\mathrm{P}<0.01)$, which was reversed when the podocytes were treated with both TGF- $\beta 1$ and SB203580 (Fig. 7D, E, K-M) or U0126 (Fig. 7I, J, O-Q). Interestingly, additional treatment with U0126 significantly decreased the miR-155 expression level $(\mathrm{P}<0.01$; Fig. 7R), while additional treatment with SB203580 resulted in no change in the miR-155 expression in TGF- $\beta 1$-treated mouse podocytes (Fig. $7 \mathrm{~N}$ ).

\section{Discussion}

Accumulating studies have demonstrated that podocytes may be potentially important therapeutic targets for glomerular nephropathy (25-28). A study on podocyte injury suggested that the targeted repair of podocytes can significantly increase the glomerular filtrate rate, decrease proteinuria, and alleviate the symptoms of disease in patients (29). However, the exact 
mechanism of podocyte injury remains unclear. In the present study, the diagnostic value of miR-155 as a biomarker in EGD was evaluated, and the dynamic expression pattern of TNF- $\alpha$ and IL-6 as pro-inflammatory cytokines and miR-155 as a post-transcriptional inflammation-related miRNA in the physiological regulation of TGF- $\beta 1$-induced podocyte injury was investigated. Notably, it was demonstrated that MAPK plays a critical role in the pathogenesis of podocyte injury. Therefore, the TGF- $\beta 1 / \mathrm{miR}-155 / \mathrm{MAPK}$ axis may be a new target for the mechanism of glomerular diseases.

Effects of TGF- $\beta 1$ on inflammatory response in mouse podocytes upon injury. The change in the expression of inflammation factors is usually associated with the progression of kidney diseases. As suggested by the report from Qiao et al (30), the expression levels of IL-1 $\beta$, TNF- $\alpha$ and TGF- $\beta 1$ were increased when podocyte apoptosis occurred, while carboxymethyl chitosan oligosaccharide can improve the condition by regulating the secretion of these inflammatory factors. In addition, Dos Santos et al (31) found that the lupus nephritis mouse model showed increased expression of IL- 6 , TNF- $\alpha$ and TGF- $\beta 1$, as well as the disappearance of foot processes and apoptosis of podocytes. A number of mechanisms are involved in the inflammatory response during podocyte injury. For example, Huang et al (9) applied the diabetic nephropathy rat model and demonstrated that the expressions of serum TNF- $\alpha$, TGF- $\beta 1$, IL- 1 and IL-6 were mediated by the PI3K/Akt signal pathway during podocyte injury. In addition, experiments by Ishikawa et al (32) showed that long-term tolvaptan therapy can improve oxidative stress-associated inflammation in podocyte injury through epithelial-mesenchymal transition, Erk 1/2 pathway and Rho-kinase pathway (32). A previous study showed that Huangkui capsule can improve adriamycin-induced kidney injury by inhibiting p38 MAPK signaling pathway, decreasing the expression of TGF- $\beta 1$ and TNF- $\alpha$ protein in the kidneys, and diminishing macrophage activation (33). Therefore, the aforementioned research has demonstrated that inflammation is an important basic pathological mechanism of podocyte injury, but the accompanied molecular pathway activation is complicated and unclear so far. The present study examined the effects of TGF- $\beta 1$ on inflammatory response in mouse podocytes upon injury. It was shown that TGF- $\beta 1$ enhanced the secretion of inflammatory cytokines, including TNF- $\alpha$ and IL-6, in a time- and dose-dependent manner, which further strengthens the critical roles of inflammation in the progression of podocyte injury-associated glomerular nephropathy.

miR-155 expression and occurrence of EGD. miR-155 has been reported to be involved in the pathogenesis of multiple kidney diseases. For instance, Saikumar et al (34) found that following acute kidney injury, the expression levels of miR-155 in renal tissues were enhanced; however, blood and urinary miR-155 levels decreased. The enhancement of miR-155 expression in renal tissues was associated with the degree of injury. miR-155 can be detected in glomeruli and proximal and distal tubules. The miR-155 levels in the urine can be significantly high in diabetic kidney disease (35). A new study involving 60 patients with late pre-eclampsia showed that there is a correlation between miR-155 expression and proteinuria, and when miR-155 is overexpressed, a decrease in nephrin production can be observed (36). A large number of studies have focused on the association between miR-155 expression levels and kidney damages, but few researchers paid attention to the cellular mechanisms between miR-155 expression and EGD. To the best of our knowledge, this is the first report that explores the potential association between miR-155 expression and the occurrence of EGD. The present study showed that miR-155 levels in the urine of patients with EGD were significantly higher compared with that of the normal controls. It is noteworthy that the ROC analysis showed that the high levels of urine miR-155 demonstrated high sensitivity and specificity in guiding the diagnosis of EGD. Neilsen et al (37) demonstrated that the target gene of miR-155 had an inhibitory effect on TGF- $\beta 1$, while the TGF- $\beta 1$ pathway played an important role in the reprogramming of miR-155 transcription. The present study demonstrated that TGF- $\beta 1$ in mouse podocytes enhanced the expression of miR-155 in a time- and dose-dependent manner, which is consistent with the transcriptional regulation of miR-155 by the TGF- $\beta 1$ pathway. However, whether miR-155 expression in our model acted back on regulating the expression of TGF- $\beta 1$ in podocytes was unknown, as soluble external TGF- $\beta 1$ was used in the model. The fact that high levels of TGF- $\beta 1$ treatment resulted in more severe phenotype of podocyte injury further supports the idea that understanding the miR-155 levels can be used for predicting the degree of podocyte injury.

miR-155 expression and inflammation responses in TGF- $\beta 1$-induced podocyte injury It is known that the expression of multifunctional miR-155 alters in several; diseases, and its expression level affects the occurrence and development of diseases. For example, in patients with pre-eclampsia, the expression of miR-155 and IL-17 increased, and further experiment showed that the overexpression of miR-155 could induce IL-17 secretion in vitro (36). The activation of the p38 MAPK pathway in Bacillus Calmette-Guérin-infected macrophages promotes the expression of miR-155, thus inhibiting the expression of nuclear factor (NF) $-\kappa \mathrm{B}$ pathway, which contributes to the increase in TNF- $\alpha$ and IL- 6 expression and leads to the survival of Mycobacterium tuberculosis (38). miR-155 is also expected to be closely associated with inflammatory diseases. In vascular smooth muscle cells (VSMCs) treated with TNF- $\alpha$, the expression levels of miR-155 increased, while cell morphology changed and cell proliferation was inhibited. The treatment with the inhibitors of NF- $\mathrm{B}$ and miR-155 can reverse these pathological changes (39). In another study, following LPS intervention, the expression levels of miR-155, IL-1 $\beta$ and TNF- $\alpha$ were significantly increased, but the inflammatory response was significantly inhibited by miR-155 knockdown (40). All the aforementioned findings indicate the important roles played by miR-155 expression and inflammation responses in pathophysiological processes. However, the association between miR-155 expression and inflammation responses in TGF- $\beta 1$-induced podocyte injury has not been reported yet. The present study showed that TNF- $\alpha$ and IL- 6 expression levels were significantly increased after TGF- $\beta 1$ intervention in podocytes, and the expression of these cytokines were positively correlated with miR-155 expression. The present findings suggest that the expression levels of miR-155 may reflect the extent of inflammatory responses in TGF- $\beta 1$-induced podocyte injury. However, further investigations on the targets of miR-155 involved in 
regulating inflammatory responses in podocytes are needed for better understanding of the exact roles of miR-155 in inflammatory-associated podocyte injury.

Interaction between miR-155 and MAPK signaling pathway. It is noteworthy that miR-155 is well known for its important role in the immune system $(41,42)$. As one of the common signal pathways that are involved in mediating podocyte injury, the MAPK signal transduction pathways can be activated by a variety of stimulating factors, such as inflammatory factors and stress, and their activation pathways are inseparable from multiple phosphorylation cascade reactions. Bioinformatic analyses and luciferase reporter assays showed that MAPK signaling and subsequent MAPK-associated pathways, including Erk 1/2 and p38, were associated with the target genes of miR-155 (43). Wang et al (44) has confirmed that swinprosin-21 was mediated by the $\mathrm{p} 38$ pathway for mitochondria-dependent podocyte apoptosis, which participated in the early stage of diabetic nephropathy. Zhu (45) found that protein arginine methyltransferases may injure podocyte and contribute to glomerular fibrosis by promoting the activation of Erk 1/2 signal pathway. However, these reactions also depend on suppressing or activating multiple signaling transduction pathways, though the mechanisms are not yet clear. Thus, studying the interaction between miR-155 and MAPK signaling pathway may represent an important approach to reveal the mechanisms of podocyte injury.

Furthermore, MAPK phosphorylation was investigated in podocyte treated with TGF- $\beta 1$ to explore the mechanisms underlying the induction of miR-155 expression upon podocyte injury. The expression levels of phospho-p38, phospho-Erk 1/2, p38, and Erk 1/2 proteins were measured, and then the levels of phosphorate tyrosine of p38 and Erk 1/2 were calculated, which verified the roles of p38 or Erk 1/2 MAPK signal transduction pathway in this process. The present study showed that a transient increase in p38 and Erk 1/2 phosphorylation was observed in response to podocyte injury after TGF- $\beta 1$ treatment. The results were in line with numerous reports documenting that MAPK pathway was involved in directing cellular responses stimulated by proinflammatory cytokines, such as TGF- $\beta 1$. It was brought to attention that the variation in the expression trends of synaptopodin, CD2AP and miR-155 lagged behind that of MAPK activation. These findings triggered the hypothesis that the potential mechanisms include a series of waterfall effects resulting from MAPK signaling. TGF- $\beta 1$ treatment remarkably altered the expression of the aforementioned biomarkers and resulted in decreased expression of synaptopodin, CD2AP protein, and mRNA; induced phosphorylation of p38 MAPK and Erk MAPK; and increased expression of miR-155. These changes could be partially abolished by SB203580 and U0126, the inhibitor of MAPK signal pathway. More significantly, during this process, the increase in miR-155 expression appeared to be reversely associated with Erk 1/2 MAPK activation. However, further experimental evidence is needed for explaining the complex molecular processes in the phosphorylation of p38 MAPK induced by TGF- $\beta 1$ during podocyte injury. It cannot be ignored that the complex mechanisms of TGF- $\beta 1$-induced podocyte injury are associated with multiple factors and steps, including genetic susceptibility, environmental influence and systemic responses, as well as the local injured podocytes can induce damage in other normal podocyte cells (46). Therefore, the present study is just a beginning, and more investigations are required to reveal the complete mechanisms.

In the present study, the association between miR-155, MAPK signaling pathway and podocyte injury after the high and low expressions of miR-155 gene could not be directly illustrated, due to lack of time, as isolation, purification and identification of these proteins would take a long time. Therefore, the absence of miR-155 up/downregulation experiments is a limitation of the present study.

miR-155 is a potential marker that can be used for the diagnosis of early glomerular disease with high sensitivity and specificity. The in vitro experiments indicated that TGF- $\beta 1$-induced podocyte injury resulted in changes in the morphology of podocytes, decreased expression levels of CD2AP and synaptopodin, and increased miR-155 expression that was positively associated with the secretion of TNF- $\alpha$ and IL-6. In addition, it was also found that the activation of MAPK signal transduction pathway, including p38 and Erk 1/2 signaling, was crucial for TGF- $\beta 1$-induced podocyte injury. The present results suggest that the expression levels of miR-155 is associated with the degree of podocyte injury, and the MAPK signal transduction pathway is involved in this process. Overall, the present study provides a significant insight on the treatment and management of glomerular diseases.

\section{Acknowledgements}

Not applicable.

\section{Funding}

This work was supported by the National Nature Science Foundation of China (grant nos. 82060133 and 81860131); the Natural Science Foundation of Guangxi (grant nos. 2019GXNSFDA245004 and 2017GXNSFAA198288); and the Scientific Research and Technical Exploitation of Baise (grant no. BK20160608).

\section{Availability of data and materials}

The datasets used and/or analyzed during the current study are available from the corresponding author on reasonable request.

\section{Authors' contributions}

XZ, QZ and XuL conceptualized and designed the study. XG provided study materials and recruited patients. XiL, ZL and $X G$ performed experiments and collected data. QQ and XD analyzed and interpreted data. XZ and QZ confirmed the authenticity of all the raw data. Manuscript writing: All authors. All authors read and approved the final manuscript.

\section{Ethics approval and consent to participate}

All the participants provided written informed consent, and this study was approved by the ethical committee of the Youjiang Medical University for Nationalities (approval no. 2019-12). 


\section{Patient consent for publication}

Not applicable.

\section{Competing interests}

The authors declare that they have no competing interests.

\section{References}

1. Zhou L and Liu Y: Wnt/ $\beta$-catenin signalling and podocyte dysfunction in proteinuric kidney disease. Nat Rev Nephrol 11: 535-545, 2015.

2. D'Agati VD, Chagnac A, de Vries AP, Levi M, Porrini E, HermanEdelstein M and Praga M: Obesity-related glomerulopathy: Clinical and pathologic characteristics and pathogenesis. Nat Rev Nephrol 12: 453-471, 2016.

3. Yaddanapudi S, Altintas MM, Kistler AD, Fernandez I, Möller CC, Wei C, Peev V, Flesche JB, Forst AL, Li J, et al: $\mathrm{CD} 2 \mathrm{AP}$ in mouse and human podocytes controls a proteolytic program that regulates cytoskeletal structure and cellular survival. J Clin Invest 121: 3965-3980, 2011.

4. Perico L, Conti S, Benigni A and Remuzzi G: Podocyte-actin dynamics in health and disease. Nat Rev Nephrol 12: 692-710, 2016.

5. Tian X and Ishibe S: Targeting the podocyte cytoskeleton: From pathogenesis to therapy in proteinuric kidney disease. Nephrol Dial Transplant 31: 1577-1583, 2016.

6. Mundel P, Heid HW, Mundel TM, Krüger M, Reiser J and Kriz W: Synaptopodin: An actin-associated protein in telencephalic dendrites and renal podocytes. J Cell Biol 139: 193-204, 1997.

7. Asanuma K, Kim K, Oh J, Giardino L, Chabanis S, Faul C, Reiser J and Mundel P: Synaptopodin regulates the actin-bundling activity of alpha-actinin in an isoform-specific manner. J Clin Invest 115: 1188-1198, 2005.

8. Shih NY, Li J, Karpitskii V, Nguyen A, Dustin ML, Kanagawa O, Miner JH and Shaw AS: Congenital nephrotic syndrome in mice lacking CD2-associated protein. Science 286: 312-315, 1999.

9. Huang G, Lv J, Li T, Huai G, Li X, Xiang S, Wang L, Qin Z, Pang J, Zou B, et al: Notoginsenoside R1 ameliorates podocyte injury in rats with diabetic nephropathy by activating the PI3K/Akt signaling pathway. Int J Mol Med 38: 1179-1189, 2016.

10. Koga K, Yokoi H, Mori K, Kasahara M, Kuwabara T, Imamaki H, Ishii A, Mori KP, Kato Y, Ohno S, et al: MicroRNA-26a inhibits TGF- $\beta$-induced extracellular matrix protein expression in podocytes by targeting CTGF and is downregulated in diabetic nephropathy. Diabetologia 58: 2169-2180, 2015.

11. Li Z and Rana TM: Therapeutic targeting of microRNAs: Current status and future challenges. Nat Rev Drug Discov 13 622-638, 2014

12. Hausser $\mathbf{J}$ and Zavolan M: Identification and consequences of miRNA-target interactions - beyond repression of gene expression. Nat Rev Genet 15: 599-612, 2014

13. Mashima R: Physiological roles of miR-155. Immunology 145: 323-333, 2015

14. Lin X, You Y, Wang J, Qin Y,Huang P and Yang F: MicroRNA-155 deficiency promotes nephrin acetylation and attenuates renal damage in hyperglycemia-induced nephropathy. Inflammation 38: 546-554, 2015

15. Chen XW, Liu WT, Wang YX, Chen WJ,Li HY, Chen YH, Du XY, PengFF,ZhouWD,XuZZ,etal:Cyclopropanyldehydrocostunolide LJ attenuates high glucose-induced podocyte injury by suppressing RANKL/RANK-mediated NF- $\kappa \mathrm{B}$ and MAPK signaling pathways. J Diabetes Complications 30: 760-769, 2016

16. Chuang PY and He JC: Signaling in regulation of podocyte phenotypes. Nephron, Physiol 111: 9-15, 2009.

17. Kaminska B: MAPK signalling pathways as molecular targets for anti-inflammatory therapy - from molecular mechanisms to therapeutic benefits. Biochim Biophys Acta 1754: 253-262, 2005

18. Kim Y, Lim HJ, Jang HJ, Lee S, Jung K, Lee SW, Lee SJ and Rho MC: Portulaca oleracea extracts and their active compounds ameliorate inflammatory bowel diseases in vitro and in vivo by modulating TNF- $\alpha$, IL-6 and IL-1 $\beta$ signalling. Food Res Int 106 $335-343,2018$
19. Han R, Zhang F, Wan C, Liu L, Zhong Q and Ding W: Effect of perfluorooctane sulphonate-induced Kupffer cell activation on hepatocyte proliferation through the NF- $\kappa \mathrm{B} / \mathrm{TNF}-\alpha /$ IL-6-dependent pathway. Chemosphere 200: 283-294, 2018.

20. Yoshimura A, Wakabayashi Y and Mori T: Cellular and molecular basis for the regulation of inflammation by TGF-beta. J Biochem 147: 781-792, 2010.

21. Chapnick DA, Warner L, Bernet J, Rao T and Liu X: Partners in crime: The TGF $\beta$ and MAPK pathways in cancer progression. Cell Biosci 1: 42, 2011.

22. Huang H, You Y, Lin X, Tang C, Gu X, Huang M, Qin Y, Tan J and Huang F: Inhibition of TRPC6 signal pathway alleviates podocyte injury induced by TGF- $\beta 1$. Cell Physiol Biochem 41: 163-172, 2017.

23. Livak KJ and Schmittgen TD: Analysis of relative gene expression data using real-time quantitative PCR and the 2(-Delta Delta $\mathrm{C}(\mathrm{T})$ ) method. Methods 25: 402-408, 2001.

24. Koshikawa M, Mukoyama M, Mori K, Suganami T, Sawai K, Yoshioka T, Nagae T, Yokoi H, Kawachi H, Shimizu F, et al: Role of p38 mitogen-activated protein kinase activation in podocyte injury and proteinuria in experimental nephrotic syndrome. J Am Soc Nephrol 16: 2690-2701, 2005.

25. Wickman L, AfshinniaF, Wang SQ, Yang Y, Wang F, Chowdhury M, Graham D, Hawkins J, Nishizono R, Tanzer M, et al: Urine podocyte mRNAs, proteinuria, and progression in human glomerular diseases. J Am Soc Nephrol 24: 2081-2095, 2013.

26. Toyoda M, Najafian B, Kim Y, Caramori ML and Mauer M: Podocyte detachment and reduced glomerular capillary endothelial fenestration in human type 1 diabetic nephropathy. Diabetes 56: 2155-2160, 2007.

27. Masum MA, Ichii O, Elewa YH, Nakamura T, Otani Y, Hosotani M and Kon Y: Modified scanning electron microscopy reveals pathological crosstalk between endothelial cells and podocytes in a murine model of membranoproliferative glomerulonephritis. Sci Rep 8: 10276, 2018.

28. Mallipattu SK and He JC: Podocyte as a direct target for treatment of glomerular disease? Am J Physiol Renal Physiol 311: F46-F51, 2016.

29. Verheijden KA, Sonneveld R, Bakker-van Bebber M, Wetzels JF, van der Vlag J and Nijenhuis T: The calcium-dependent protease calpain-1 links TRPC6 activity to podocyte injury. J Am Soc Nephrol 29: 2099-2109, 2018

30. Qiao J, Liu Y, Jiang Z, Yang Y, Liu W and Han B: Preparation and renoprotective effects of carboxymethyl chitosan oligosaccharide on adriamycin nephropathy. Carbohydr Polym 201: 347-356, 2018

31. Dos Santos M, Poletti PT, Favero G, Stacchiotti A, Bonomini F, MontanariCC,Bona SR, Marroni NP, Rezzani R and Veronese FV: Protective effects of quercetin treatment in a pristane-induced mouse model of lupus nephritis. Autoimmunity 51: 69-80, 2018.

32. Ishikawa M, Kobayashi N, Sugiyama F, Onoda S and Ishimitsu T: Renoprotective effect of vasopressin v2 receptor antagonist tolvaptan in Dahl rats with end-stage heart failure. Int Heart J 54: 98-106, 2013

33. Tu Y, Sun W, Wan YG, Che XY, Pu HP, Yin XJ, Chen HL, Meng XJ, Huang YR and Shi XM: Huangkui capsule, an extract from Abelmoschus manihot (L.) medic, ameliorates adriamycin-induced renal inflammation and glomerular injury via inhibiting p38MAPK signaling pathway activity in rats. J Ethnopharmacol 147: 311-320, 2013.

34. Saikumar J, Hoffmann D, Kim TM, Gonzalez VR, Zhang Q, Goering PL, Brown RP, Bijol V, Park PJ, Waikar SS, et al: Expression, circulation, and excretion profile of microRNA-21, -155, and -18a following acute kidney injury. Toxicol Sci 129: 256-267, 2012.

35. Beltrami C, Simpson K, Jesky M, Wonnacott A, Carrington C, Holmans P, Newbury L, Jenkins R, Ashdown T, Dayan C, et al: Association of elevated urinary miR-126, miR-155, and miR-29b with diabetic kidney disease. Am J Pathol 188: 1982-1992, 2018.

36. Yang $X$, Zhang $J$ and Ding Y: Association of microRNA-155, interleukin $17 \mathrm{~A}$, and proteinuria in preeclampsia. Medicine (Baltimore) 96: e6509, 2017.

37. Neilsen PM, Noll JE, Mattiske S, Bracken CP, Gregory PA, Schulz RB, Lim SP, Kumar R, Suetani RJ, Goodall GJ, et al: Mutant p53 drives invasion in breast tumors through up-regulation of miR-155. Oncogene 32: 2992-3000, 2013.

38. Yao J, Du X, Chen S, Shao Y, Deng K, Jiang M, Liu J, Shen Z, Chen X and Feng G: Rv2346c enhances mycobacterial survival within macrophages by inhibiting TNF- $\alpha$ and IL- 6 production via the $\mathrm{p} 38 / \mathrm{miRNA} / \mathrm{NF}-\kappa \mathrm{B}$ pathway. Emerg Microbes Infect 7: 158,2018 
39. Park M, Choi S, Kim S, Kim J, Lee DK, Park W, Kim T, Jung J, Hwang JY, Won MH, et al: NF-kB-responsive miR-155 induces functional impairment of vascular smooth muscle cells by downregulating soluble guanylyl cyclase. Exp Mol Med 51: 1-12, 2019.

40. Peng W, Zhao N, Liu Q, Nie C, Qing C, Shao Q, Liu F, Qian K and Ding C: MicroRNA-155 reduces inflammatory response induced by lipopolysaccharide in alveolar macrophages. Zhonghua Wei Zhong Bing Ji Jiu Yi Xue 30: 1061-1065, 2018 (In Chinese).

41. Mann M, Mehta A, Zhao JL, Lee K, Marinov GK, Garcia-Flores Y, Lu LF, Rudensky AY and Baltimore D: An NF-kappaB-microRNA regulatory network tunes macrophage inflammatory responses. Nat Commun 8: 851, 2017.

42. Joyce CE and Novina CD: miR-155 in acute myeloid leukemia: Not merely a prognostic marker? J Clin Oncol 31: 2219-2221, 2013.

43. Chakraborty C, Sharma AR, Patra BC, Bhattacharya M, Sharma G and Lee SS: MicroRNAs mediated regulation of MAPK signaling pathways in chronic myeloid leukemia. Oncotarget 7: 42683-42697, 2016.
44. Wang RM, Wang ZB, Wang Y, Liu WY, Li Y, Tong LC, Zhang S, Su DF, Cao YB, Li L, et al: Swiprosin-1 promotes mitochondria-dependent apoptosis of glomerular podocytes via P38 MAPK pathway in early-stage diabetic nephropathy. Cell Physiol Biochem 45: 899-916, 2018.

45. Zhu Y: PRMT1 mediates podocyte injury and glomerular fibrosis through phosphorylation of ERK pathway. Biochem Biophys Res Commun 495: 828-838, 2018

46. Fogo $\mathrm{AB}$ and Kon V: The glomerulus - a view from the inside the endothelial cell. Int J Biochem Cell Biol 42: 1388-1397, 2010.

(i) $($ ) This work is licensed under a Creative Commons Attribution-NonCommercial-NoDerivatives 4.0 International (CC BY-NC-ND 4.0) License. 